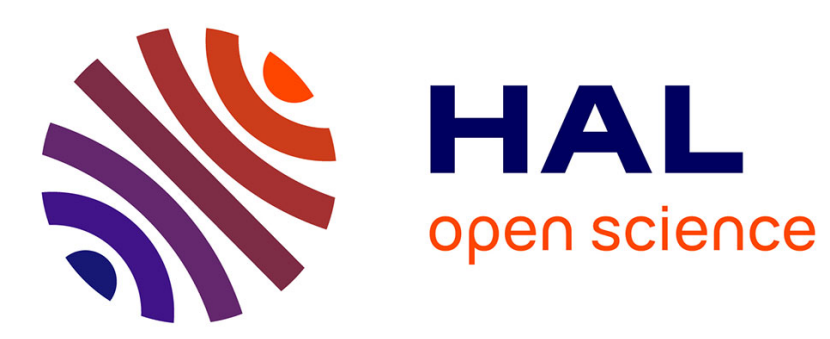

\title{
Towards a modelling and optimisation of the recovery of marine floating plastic
}

Nicolas Maslov, Loïc Salmon, Christophe Claramunt

\section{To cite this version:}

Nicolas Maslov, Loï Salmon, Christophe Claramunt. Towards a modelling and optimisation of the recovery of marine floating plastic. W2GIS 2020, Nov 2020, Wuhan, China. hal-03365821

\section{HAL Id: hal-03365821 \\ https://hal.science/hal-03365821}

Submitted on 5 Oct 2021

HAL is a multi-disciplinary open access archive for the deposit and dissemination of scientific research documents, whether they are published or not. The documents may come from teaching and research institutions in France or abroad, or from public or private research centers.
L'archive ouverte pluridisciplinaire HAL, est destinée au dépôt et à la diffusion de documents scientifiques de niveau recherche, publiés ou non, émanant des établissements d'enseignement et de recherche français ou étrangers, des laboratoires publics ou privés. 


\title{
Towards a modelling and optimisation of the recovery of marine floating plastic
}

\author{
Nicolas Maslov ${ }^{1}$, Loïc Salmon ${ }^{2}$, and Christophe Claramunt ${ }^{1}$ \\ 1 Naval Academy Research Institute, 29160 Lanvéoc, France \\ 2 Université de Bretagne Occidentale, 29200 Brest, France
}

\begin{abstract}
The recovery of marine plastic litter has been recently recognised as one of the world greatest environmental challenge. While many recent initiatives are oriented towards the recovery of micro plastics, there is still a need for the development of observation and in situ capabilities that will provide appropriate positional data to combat such critical pollution phenomenon. The experimental research developed in this paper introduces a methodology for geo-locating and collecting plastic wastes in a maritime environment. The approach is spatially and temporally-based in the sense plastic wastes are tracked over time according to some meteorological conditions (i.e., winds, currents, tides). Overall, predicting plastic waste displacements constitutes a first step to an optimization process whose objective is to collect plastic debris in littoral zones using a dedicated ship.
\end{abstract}

Keywords: Marine Litter · Macro-plastic $\cdot$ Trajectory prediction $\cdot$ Route optimisation.

\section{Introduction}

Plastic pollution is considered as a major environmental problem [1], with three trillion of plastic wastes populating the oceans, weighting about 322 million tons[2]. This growing accumulation in seas and oceans constitutes a major risk for the marine ecosystems [3], particularly because of its introduction into the food chain. Furthermore, it has been observed that anthropogenic marine debris may cause physical harms to humans when debris is ingested via seafood [4]. Last, marine plastic pollution also has a significant impact on tourism in coastal environments. Plastics are mainly produced from substances extracted from oil and natural gas. First highlighted for their remarkable mechanical properties, these materials are now suffering from the problematic of their end of life due to their slow degradation. During the wearing process, plastics fragment, spread in nature and take 500 to 1000 years to decompose [5].

Plastic waste can be categorised according to their dimensions, and into three types: macro-plastic, meso-plastic and micro-plastic [6], EU [7], NOAA [8]. A distinction can be made between micro-plastics for plastic debris sizing less than $5 \mathrm{~mm}$, meso-plastics for dimensions between $5 \mathrm{~mm}$ and $2.5 \mathrm{~cm}$ and macroplastics for plastic debris larger than $2.5 \mathrm{~cm}$. However, it has been observed that 
researches dealing with marine plastic pollution mainly concerns micro-wastes. [9] [10].

The objective of our preliminary research is to introduce a methodology to first observe, model and map macro-plastic phenomena at sea, and that will facilitate the recovery of large floating macro-plastic areas in coastal marine environments. Macro-plastics are generally large plastic elements such as bags, water bottles or fishing equipment. The main idea behind our study is to combine different observation resources (i.e., high resolution satellite data) with in situ observations in order to provide a decision-aid mechanism for a recovery ship whose objective will be to collect and recover large plastic areas in coastal environments. Such large plastic patches are generated by convergence of oceanographic currents and meteorological conditions in the ocean and which have been already observed and studied [11][12][13]. Indeed, coastal areas are appropriate targets, especially close to river mouths, as it has been observed that each year rivers discharge about 2 million tons of plastic waste [5].

Before being collected, macro-plastic should be identified and monitored. So far two main means of observation can be operated such as remote sensing techniques using conventional or radar images or in situ observations. However, and to the best of our knowledge, still not completely convincing approaches have been developed to successfully observe and track macro-plastic areas over time in marine areas. This motivates our search for an integrated approach, based on a combination of high-resolution satellite data with in situ observations. A data modelling and optimisation framework is developed, and whose objective is to track macro-plastic areas overs time and to visualise them in a dynamic cartographical environment. The final objective is to optimise a ship trajectory to collect those plastic macro-waste taking into account their drift.

The remain of this article is organized as follows. Section 2 introduces the data acquisition sources and provides details of a marine observation protocol. Section 3 presents extracting and monitoring approach and the underlying database model. Section 4 develop two drift models depending on marine currents applied to floating waste, the first one proposed is deterministic while the second one is stochastic to handle conditions uncertainty and variability at sea, the objective being to optimise ship trajectories when recovering marine floating plastic. Section 5 presents a case study that illustrates the collection model while Section 6 concludes the paper and outlines future developments.

\section{Marine waste patches observation and recovery}

The main principles of the derivation of an optimal route to efficiently collect plastic waste at sea are described in the following figure 1 . This requires first of all (1) a data model for the recovery and management of waste patch geolocated data. Secondly (2) the data model must take into account fusion and update aspects while different observation sources are available and waste patch are constantly moving due to currents and winds. (3) An extraction of a plasticwaste density map moving according with a drift model of the waste patch. This 
process should also be involved in the regular update an underlying database. Finally (4) a decision support algorithm to derive the most favourable route to collect as much as possible plastic wastes while taking into account the limited range of a vessel. A series of contextual parameters will be taken into account such as the amount of collected plastic, the time of sailing or the energy consumed by the boat (i.e., an optimised route would avoid currents and bad weather conditions).

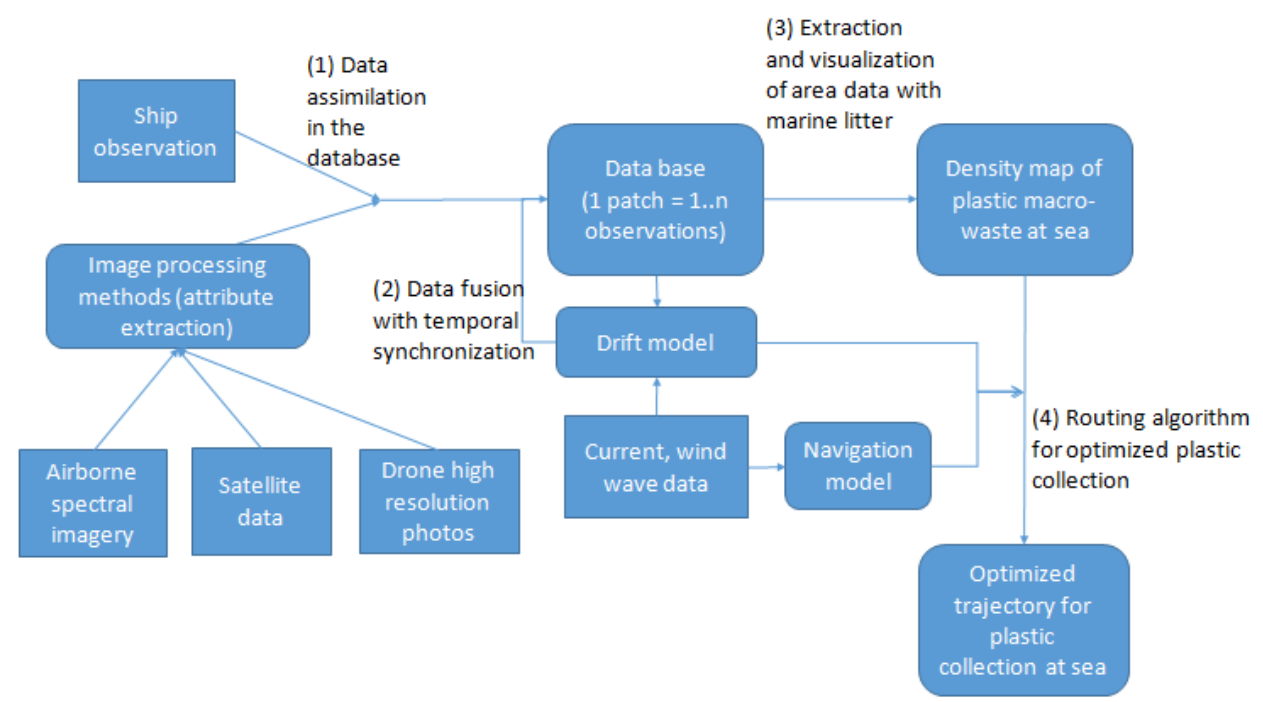

Fig. 1. Observing and collecting macro-plastic wastes at sea: main principles

It clearly appears that a combination of complementary observation methods is necessary in order to model and track waste patches at sea [14]. Indeed, each observation technology provides a specific information mean to be recovered at different resolutions (as well as at variable costs). In the case of plastic waste at sea, aerial or satellite images allow, for example, a relative evaluation of the location and estimation of the surface area of a floating waste patch. While the temporal resolution is limited by the orbit characteristics for satellite images and the availability of satellite images, for airborne systems a data acquisition implies the planning of an observation campaign this being not always easy and probably a relatively costly operation. Moreover, satellite orbits considerably vary considerably (i.e., from a few days to 1 month); aircraft are generally limited to about ten flight hours, and about thirty hours for drones. Weather constraints are also a constraint for all optical observation instruments but less so when it comes to microwaves [14]. Due to many different types and size of plastics, solutions based on satellite and airborne remote sensing tools for assessing ocean plastic pollution are not completely efficient when applied alone. 
However, remote sensing technologies with moderate to high temporal, spectral and spatial resolutions have the potential to be a reliable source of quantitative and qualitative information at wide geographical scale [15]. In [16], a first step towards floating marine macro plastics using hyperspectral remote sensing algorithm is developed, due to the unique spectral signature of polymers in nearinfrared part of electromagnetic spectrum. High resolution photo have been used in coastal detection in [17] and [18] for instance. Overall, and as a complete temporal availability of high resolution images is not a guarantee, complementary in situ additional observation data is required. Last, and as tracking plastic waste areas is a key issue for recovery missions, such integrated observations should be therefore and ideally coupled with oceanographic drift models.

An efficient way to collect detailed information on the characteristics of floating waste is by in situ observation surveys. Recently, a data acquisition protocol for marine macro-plastic collection and waste-to-energy transformation has been suggested ${ }^{3}$. Voluntary observations come from crews on ships. The surveys are in paper format but a willing to develop a numerical format is under consideration, with the objective to provide an open database. Three observation situations of floating waste patches are defined according to the possibilities of the crew and the vessel. Considering the speed of the boat and the willing of people on board to report information, an observation can be a rapid visual estimation of the waste, by completing a general observation sheet and taking photos or videos in the basic case. this gives a succession of GPS-based location in a more refined case with information about distance between the boat and the waste. Finally, some other information can be provided concerning the waste composition.

\begin{tabular}{|c|c|c|c|c|c|c|}
\hline \multicolumn{7}{|c|}{ PLASTIC WASTE OBSERVED FROM SHIP } \\
\hline \multicolumn{7}{|c|}{ MATERIAL OBSERVATION SHEET } \\
\hline \multicolumn{3}{|c|}{ DATE : } & & \multicolumn{2}{|c|}{ START TIME (UTC) : } & \multirow[b]{2}{*}{$>50 \mathrm{~cm}$} \\
\hline & $\dot{\omega} \vec{\Sigma}$ & $\begin{array}{l}\frac{\alpha}{d x} \\
\frac{\alpha}{2} \\
0\end{array}$ & Quantify the objects according to the following size categories: & $<10 \mathrm{~cm}$ & $10 \mathrm{~cm}<\ldots<50 \mathrm{~cm}$ & \\
\hline \multirow{7}{*}{$\begin{array}{l}\frac{u}{\tilde{n}} \\
\frac{\pi}{\alpha} \\
\frac{\pi}{n}\end{array}$} & G2 & & Bags & & & \\
\hline & G6 & 4 & Bottles & & & \\
\hline & G18 & 13 & Crates and containers & & & \\
\hline & G38 & & Cover / Packaging & & & \\
\hline & G39 & & Gloves & & & \\
\hline & G45 & & Mussels nets, Oyster nets & & & \\
\hline & G48 & & Synthectic rope & & & \\
\hline
\end{tabular}

Fig. 2. Extract of The SeaCleaners observation sheet, material classification based on TSG-ML report

The nature of the waste contained in floating debris patch can be recorded via these surveys. Six major families of floating waste have been categorised by the TSG-ML (Technical Subgroup On Marine Litter under the Marine Strategy

\footnotetext{
${ }^{3}$ https://www.theseacleaners.org/en
} 
Framework Directive) and the OSPAR Commission [7]. The waste categories includes rubber, clothing/textiles, paper/cardboard, treated/worked wood, metals and plastic materials. Plastic wastes can also be classified in subcategories as follows (cf. figure 2), according to their nature plastic elements can not be treated in the same way.

\section{Extraction methodology and data management for collecting plastic macro-waste at sea}

\subsection{Challenges for wastes patches tracking at sea}

Accordingly, several issues should be considered in relation with the respective data sources.

- Data quality. A first issue concerns data quality as incoming information could be incomplete or uncertain according to the data or observation source. For instance, for in situ information, the exact position of the waste could be imprecise but the observation can provide information concerning the waste patch composition. On contrary, data from satellites provides better information concerning the spatial extent of the waste patch but information for the composition could be incomplete. Those differences of quality necessitate fusion mechanisms to characterize a waste patch.

- Data fusion. A second issue concerns data comparison and fusion. Indeed, for a same macro-waste, different observations from different sources could have been done. However this implies to determine to which degree two given observations are related to the same waste patch by finding some similarities between observations that can be cross-related. Those similarities concern the spatial extent and the general composition of waste patch and to compare information in accordance with currents and meteorological conditions. The merging process depends on the quality of collected data (i.e., imagery process for remote sensor and observation condition for in situ observations). The registration of images acquired by different sensors is a challenging task, as it requires space and time registration and synchronisation. However many works have been developed for tracking object issues, methods used to tackle these problem are for instance the contour or any invariant feature detection or similarity measure relying on mutual information [24]. In the case of asynchronous time data collection, a prediction of movement is also needed.

- Data and synopsis update. This information fusion may be performed and extended using specific mechanisms to identify redundant or complementary information concerning one waste patch and update the database regularly. Some approaches so-called hybrid (i.e., merging results extracted from data stored in database with streaming data) could be useful [25], for continuously integrating new data in the database as well as updating synopses related to specific queries (i.e., density map of waste patch at sea). 


\subsection{A data model for macro-waste plastic observation}

As previously mentioned, waste patch geo-location data can be integrated by complementary protocols: from image data recorded by satellites, aircrafts and drones to in situ observations. As illustrated by figure 3, different complementary data sources are available for geo-locating macro-plastic areas (i.e., in situ visual observation, satellite or aerial images). Firstly, such data can be collected from the analysis of image data, using either satellite or aerial images from which, using analysis and filtering methods, the locations of plastic macro-waste can be extracted and approximated. As far as the location and associated semantic data are associated, the objective is to setup a visual and cartographic application that will provide basic elements (geo-location, surface of the macrowaste, approximate composition of marine litter) that can be even completed by some additional contextual data (e.g., photographs, comments). As waste patches are very likely to exhibit elements of different nature (e.g., clothes, paper, cardboard), documenting these compositions is also taken into account by the different composition tables identified by our model (i.e., other categories of marine litter exists, but we have only considered rubber and plastic elements for simplicity purposes). The following diagram describes the database model used for observing the distribution of marine litters and more specifically plastic macro-wastes at sea (figure 3).

For each observation, a polygon (or a point as a first consideration) that denotes a waste patch at a given observation time should be identified and recorded in the database. The extent and description observed for a given macro waste depends on the mean of observation. The model can associate two (or more) observations taken at different times when their their respective positions can be cross-related and if their characteristics provide sufficient similarities.

The data model for an assimilation of waste patch data has been defined and implemented within PostGIS. This favours further visualizations of waste patches according to their composition and spatial properties over time using appropriate queries. Those queries are more specifically density queries. For instance, a useful case is to have the location of all macro-wastes with a higher percentage of plastic and with a significant extent. For visualizations purposes, different layers can be considered according to the composition of the macrowastes for instance.

\subsection{Visualization of geolocated plastic macro-wastes at sea}

The degree of plastic related to a marine litter, its drift/distance speed and weather conditions may influence the capability to recover an observed macrowaste. Indeed, marine litters with a strong plastic composition will be preferred because of the pyrolysis system on board the boat, marine litter moving away from the ship's range or present in unfavourable navigation areas will be neglected.

The implemented QGIS database supports queries and visualizations that can implicitly explain some emerging characteristics such as the nature of marine litters, their dimensions and drift according to currents. 


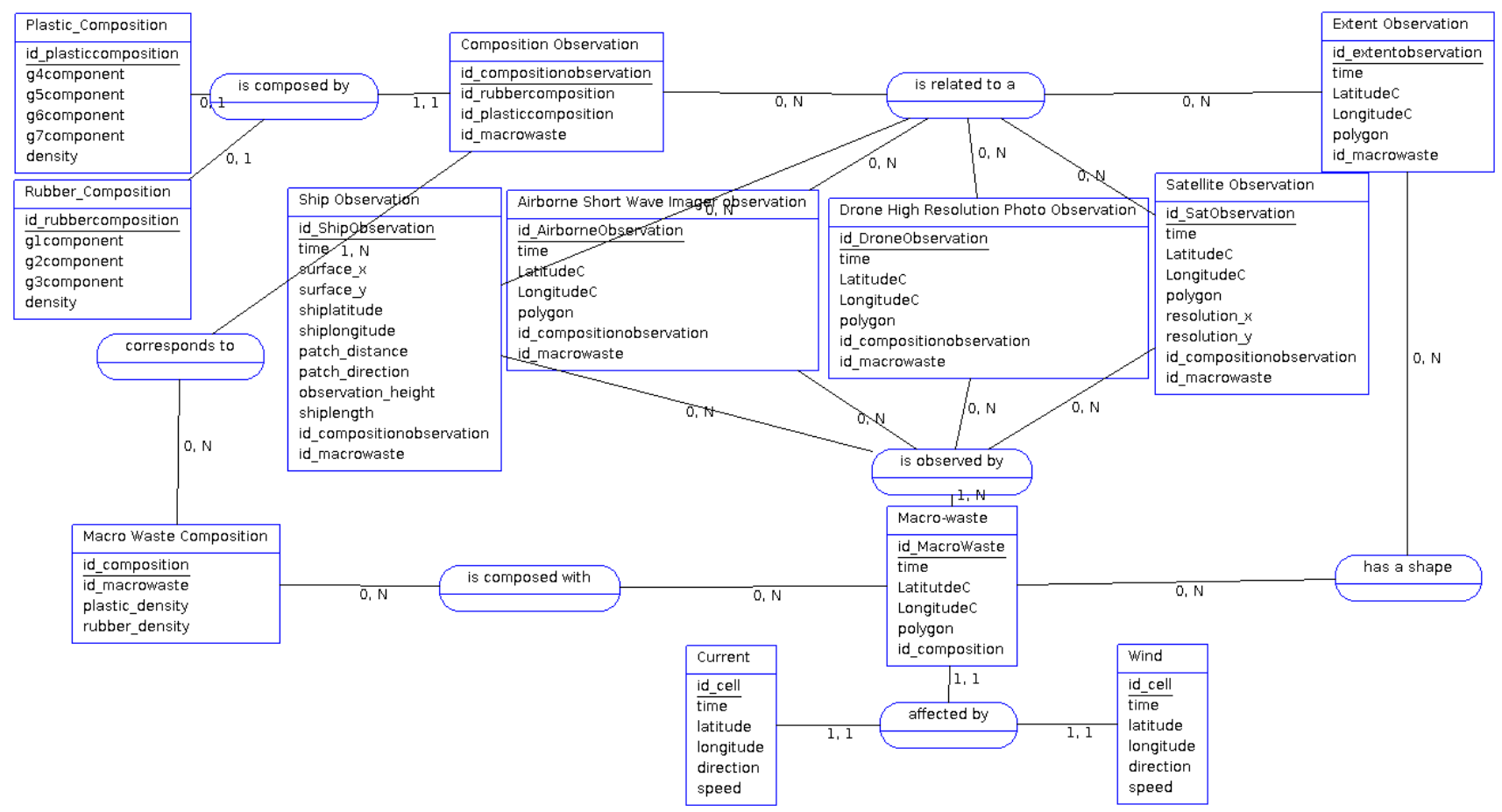

Fig. 3. Data model for macro-waste plastic observation at sea

Figure 4 illustrates the macro-waste present (in pink on the map) whose plastic concentration is relatively high. The white spaces represent macro-wastes in accordance with their spatial extent. The purple areas represent the areas for which the currents are low and for which the macro-waste present shouldn't move so much.

This map provides basic information on the distribution of these elements at sea, as well as their composition and surface area, this being useful for a first visualization of these wastes. However, the previous requests only supports visualization of the distribution of these macro-wastes without taking into account their drift, particularly in relation to meteorological and oceanographic elements. In the following part, a current drift estimation method is then proposed to generate a probability map at a time $t+\delta$.

\section{Drift prediction model of floating debris affected by marine currents}

In this section two methods for evaluating marine currents are introduced. The first one is deterministic and the floating debris move along the current direction, while the second one discussed is stochastic to take into account the high vari- 
N.Maslov et al.

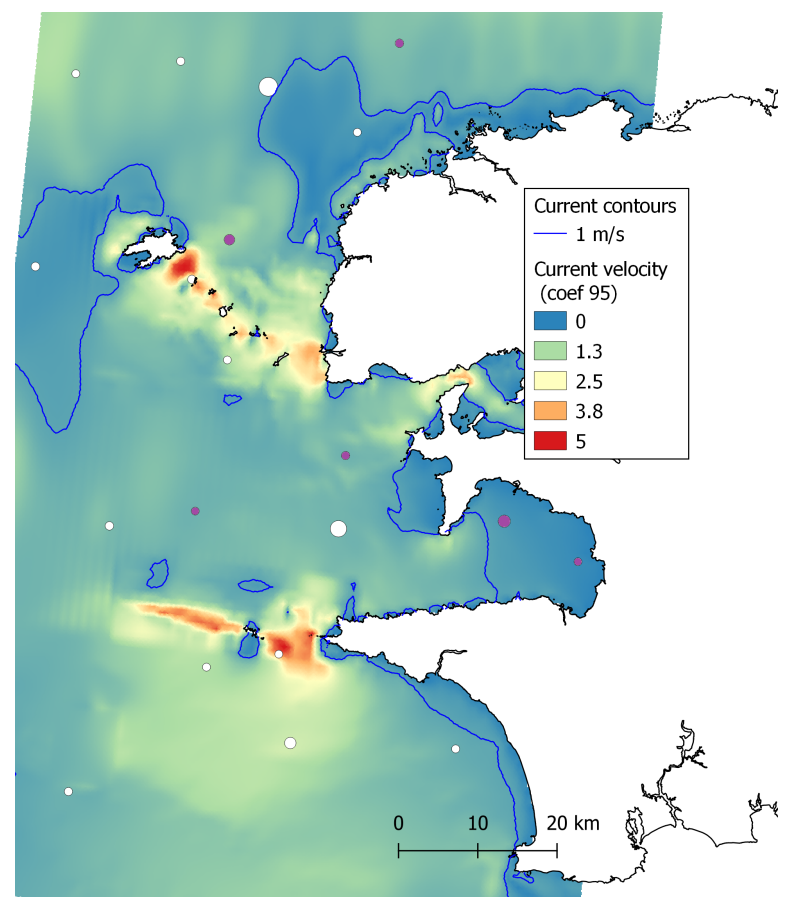

Fig. 4. Distribution of plastic macro-waste at sea near Brest

ability of conditions at sea. The two methods are then applied and compared to determine the one which corresponds better to the movement of floating debris. The objective is to propose a preliminary trajectory of floating waste patches in order to plan a navigation route to collect them. The main principles of the presented methods are to follow current direction. A similar method has been used in [22] where a simple estimation of particle displacement with time is derived from its last known position driven by the background ocean surface currents derived from the nearest data grid assuming negligible waves and wind-induced leeway effect. This method is itself similar to the conventional progressive vector diagram which has been used to estimate transport in the coastal ocean from velocity and time series [20]. These methods have been used in the context of search and rescue application, they provide a rapid response to the recovery of a missing person at sea. In this paper two methods to derive current from data with the same approach type are presented in the next subsections.

Definition 1: Floating waste patch. A patch $A$ is defined as a polygon, its centroid is denoted $C$, localised by its latitude and longitude, LatC and LongC, and $L$ and $l$ the length and width of the waste patch. 
As a first hypothesis, if the wasted patch is affected by marine currents, the drift is considered to be applied on its centroid.

Definition 2: Regular grid. A regular grid denoted $G$ is used to define the region of interest with a size cell noted Size $e_{\text {cell }}$. Each point of the grid, $P_{i}$, area the location where the current are known for each time $T_{j}$ taken at a regular time step, meaning $T_{j+1}-T_{j}$ is constant.

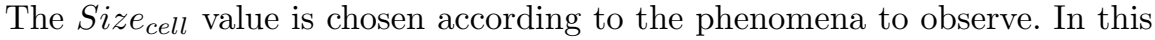
case, the resolution of the grid is determined by current data provided by SHOM ${ }^{4}$. Data currents are denoted as $C\left(P_{i}, T_{j}\right)$, and they are composed by their velocities $V\left(P_{i}, T_{j}\right)$ and directions $A\left(P_{i}, T_{j}\right)$ at the points $P_{i}$ and time $T_{j}$.

In the next section, $C(p, t)$ denotes the current which characteristics are needed. $P_{p / n}$ is denoted as the nth nearest points of $p$. In the case of a regular grid $n=4$, actually the four points of the cell in which $p$ is located. If the data is usually given according to a regular grid, the proposed method may be applied to different grid resolutions by modulating the number of nearest points. The distance between $p$ to $P_{p / n}$ is denoted $D_{n}$.

\subsection{Deterministic process for spatio-temporal current estimation}

With this method the calculation of $C(p, t)$ begins with two spatial interpolations performed between the four current data points of the cell $P_{p / n=1 . .4}$ at the time $T_{j}$ and $T_{j+1}$ with $T_{j}<t<T+j$, figure 5 .

The first spatial interpolation at $T_{j}$ is computed as follows:

$$
C\left(p, T_{j}\right)=\frac{1}{\sum_{i=1}^{n} 1 / D_{i}} \cdot \sum_{i=1}^{n} \frac{1}{D_{i}} \cdot C\left(P_{p / i}, T_{j}\right) \text { with } i \in\{1, . ., 4\}
$$

A temporal interpolation is finally performed to compute $C(p, t)$ between the two spatial interpolations at $C\left(p, T_{j}\right)$ and $C\left(p, T_{j}+1\right)$.

However, a linear interpolation may not describe the current flow correctly, particularly in shallow waters where the bathymetry for instance may largely affect the current characteristics from an observation data point to another. Instead, a stochastic method is proposed, where the floating waste is subject to be affected by a single current data point.

\subsection{Stochastic process for spatio-temporal current estimation}

In this stochastic process, four temporal interpolations are made between $T_{j}$ and $T_{j+1}$ for the points $P_{p / n=1 . .4}$ in order to obtain the currents $C\left(P_{p / n=1 . .4}, t\right)$. Instead of performing a spatial interpolation between these four currents, the

\footnotetext{
${ }^{4}$ https://www.shom.fr/
} 


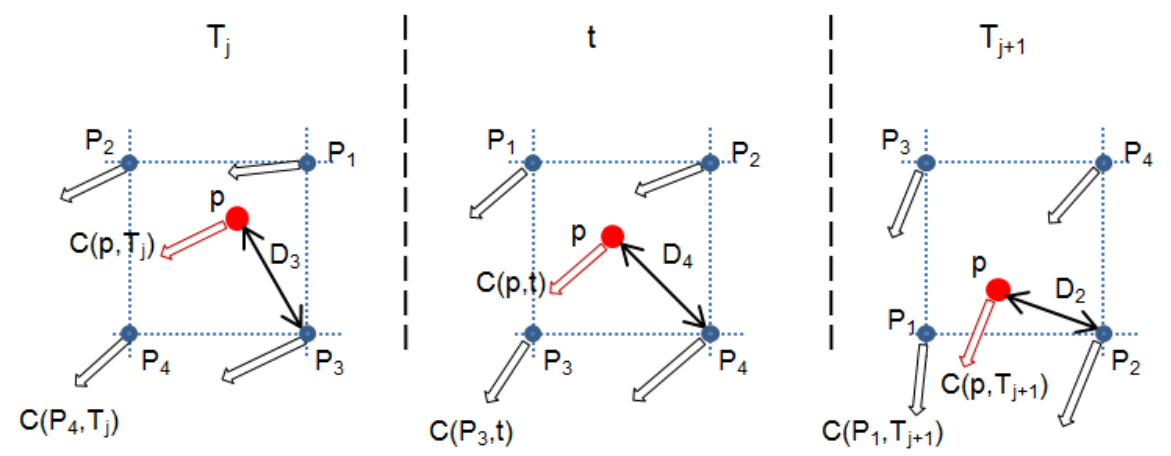

Fig. 5. Estimation of marine current at time $t$ and location $p$

current values are affected accordingly to a single data current data point following a probability law:

$$
\operatorname{Prob}\left\{C\left(P_{p / k}, t\right)\right\}=\frac{1}{\sum_{i=1}^{n} 1 / D_{i}} \frac{1}{D_{k}} \text { with } n=4 \text { and } k \in\{1, ., n\}
$$

This method generates a corridor that denotes the possible presence of waste over a period time. The corridor is obtained by plotting a large number of possible waste trajectories, figure 6 . This figure shows a set of probable trajectories for floating waste where trajectories have been derived by the method introduced above. This corridor shape of the trajectory can be explain by the location of the waste in open sea where the difference of current characteristic between two data point is very low (current vectors almost parallel). If the waste is located in coastal zone, in shallow water, near island where the current are affected by low bathymetry, trajectories be more diffused.

\subsection{Intersection estimation between ship and floating debris trajectories}

A first model of the ship behaviour and displacement is considered to model the collection of floating waste at sea. The boat direction to the waste is assumed as a straight line. This course is actually named ground track. The surface road is composed by the current drift and the ground track. The distance travelled by the ship, between its initial position and the waste, is calculated over a set of time intervals $\{T, T+1\}$, for each time interval the current velocity is estimated (see section 4.2) to obtain the drift velocity due to the current. The real heading, the corrective course to steer sets by the navigator to compensate the drift and move towards the waste in a straight line, is also calculated, figure 7 . Currents coming from the stern of the vessel will therefore tend to increase the navigation distance, while those coming from the bow will decrease ship velocity. A constant 


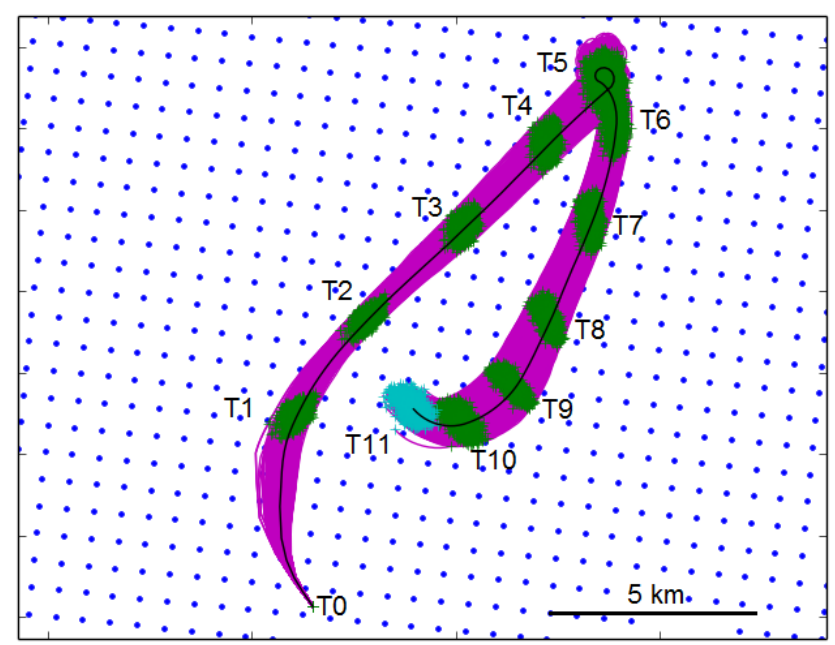

Fig. 6. Plot of 1000 trajectories with the 'stochastic' method in magenta, the green points represent the last position of waste after 12 hours drift. The trajectory with the interpolation method is given in black.

cruising speed is also assumed for the vessel velocity.

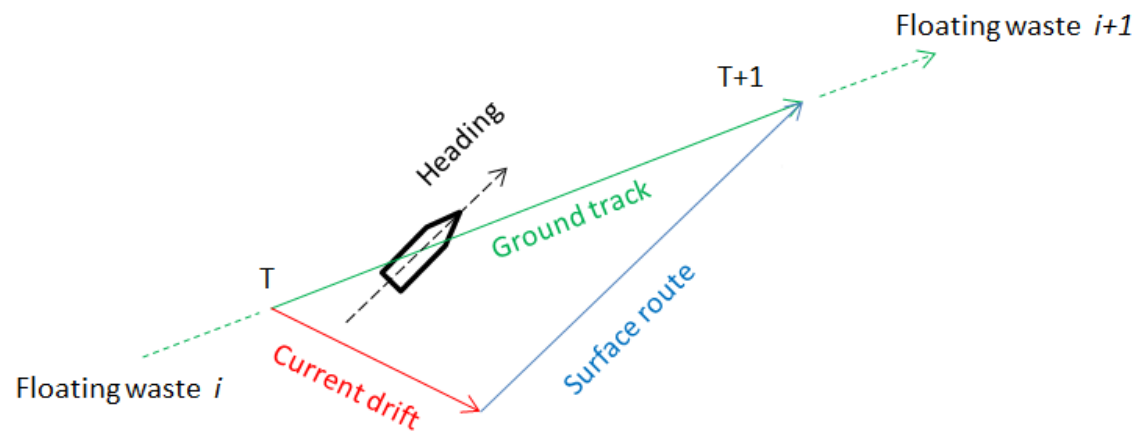

Fig. 7. Route followed by a ship subject to a marine current

The intersection calculation between the ship and the waste patches trajectories is performed according to the algorithm 1. As a similar way to the displacement of the waste, with a time step calculation, the new position of the ship and the current characteristics affecting the vessel are estimated. As the vessel speed is significantly higher than the current velocity, the time step for 
calculating the vessel trajectory is lower than that the one used to calculate the floating debris.

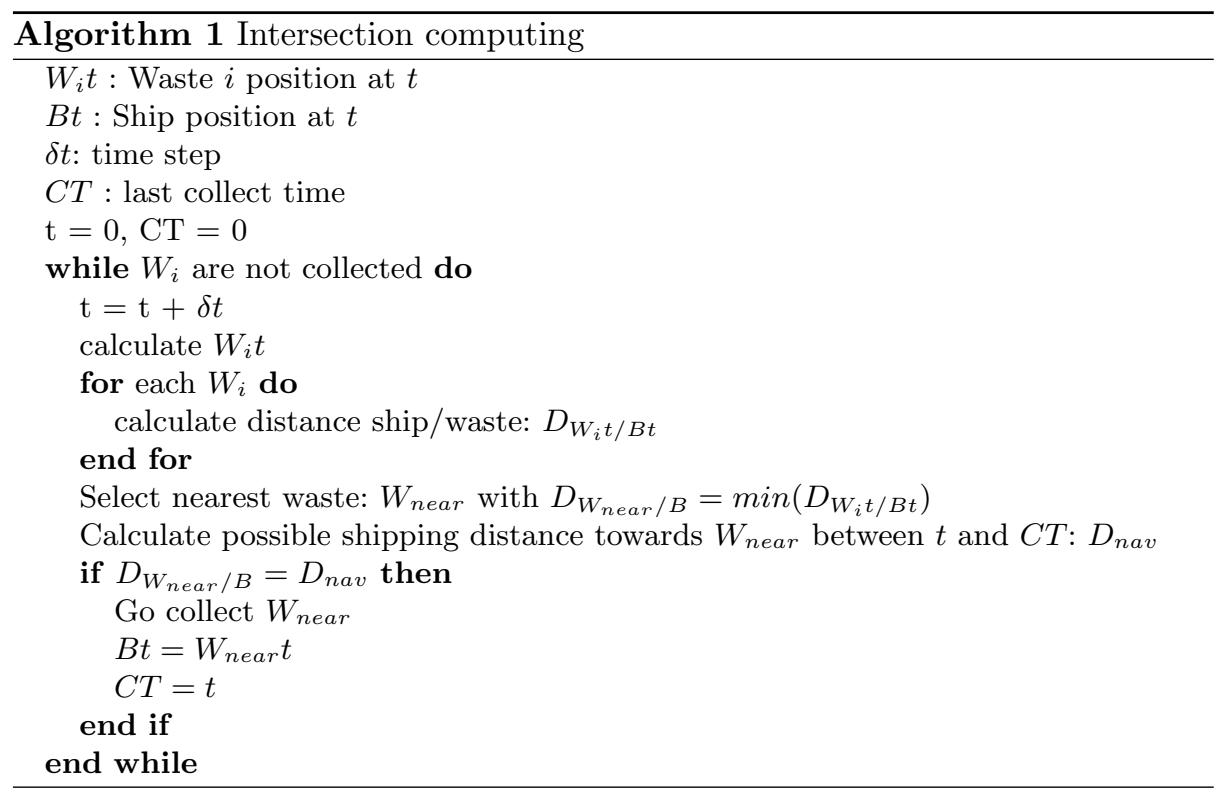

\section{Application case}

To illustrate the behaviour of floating debris and ship trajectory models, as well as the recovery algorithm, a case study in the Iroise Sea, North West part of France, has been developed. Current data are provided by SHOM (Service Hydrographique et Océanographique de la Marine) around the Brest area in the Iroise Sea. The mesh size used is approximately 700 meters in accordance with the file format provided by SHOM. One thousand waste drift simulations around Brest have been run using the stochastic method presented above. Depending on the distribution of the marine litter for each of the simulations, a density probability map was generated (see Figure 8). Considering the number of times a macro-waste patch lies in a cell, a score is attributed to this cell. In the map, the color of the cells corresponds to the score of presence for a plastic macro-waste in order to visualize the probability of presence for plastic macro-waste.

The interest of such a map is multiple, it allows first of all to take into account the limit of our plastic drift model by integrating a random dimension. It then allows us to have an approximation of the distribution of waste, better than previous visualisations with QGIS which only allowed us to have a rendering of the marine litter at observation time. Finally, this map is the first essential 


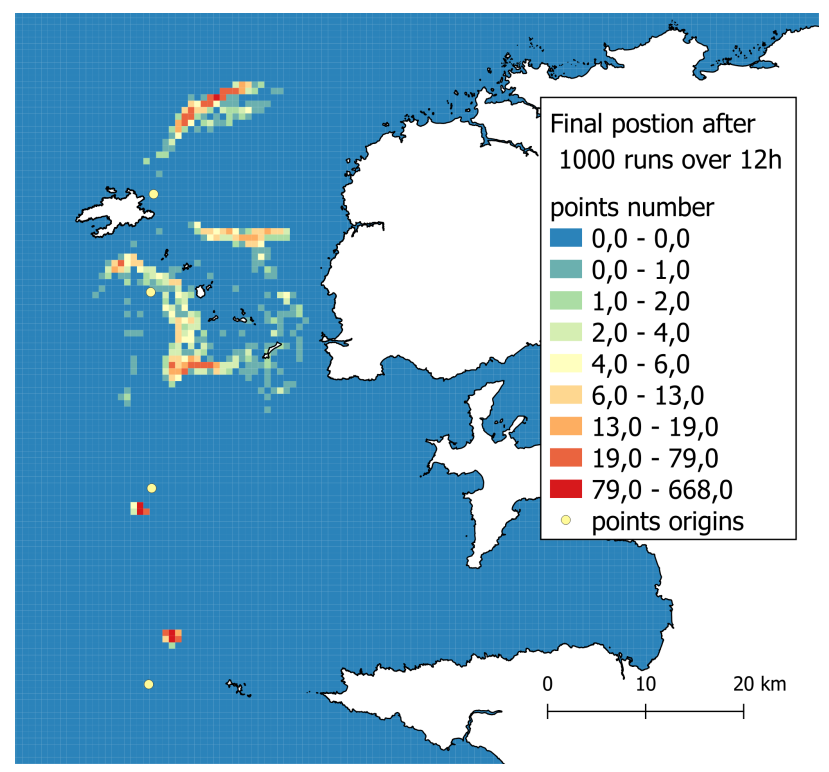

Fig. 8. Example of density map derived from four floating debris at sea

element before setting up an algorithm to determine the best route for the boat to optimize the quantity of plastics collected.

In a second case, a ship navigating from the South must collect four waste patches of floating debris. This area is well known for its particular and strong tidal currents (particularly in the vicinity of the islands and islets).

Figure 9 shows the position of the waste at the initial time (red cross), their trajectory over a period of 12 hours (black lines), the position of the vessel at initial time (green cross), its trajectory (green line) and respectively the collection points of waste (intersection of the trajectories of waste and the vessel) in green and magenta, for a vessel subject and not subject to currents. The tendency of the waste trajectory to turn back is due to the inversion of tidal currents every 6 hours approximately in the region (semi-diurnal tide). By considering a navigation speed of $5 \mathrm{~m} / \mathrm{s}$, the waste patches are collected 2 hours and 6 minutes, 4 hours and 24 minutes, 7 hours and 42 minutes and 9 hours after the initial time.

The initial time is taken 6 hours before high tide (beginning of the flow tide), the current is favourable to the ship, collecting the first two waste patches faster than a ship that would be not affected by current. About 6 hours later, the current reverses (beginning of the ebb tide). The ship is mainly subject to counter flow, the waste collection times are delayed compared to a ship that would not be subject to current. 


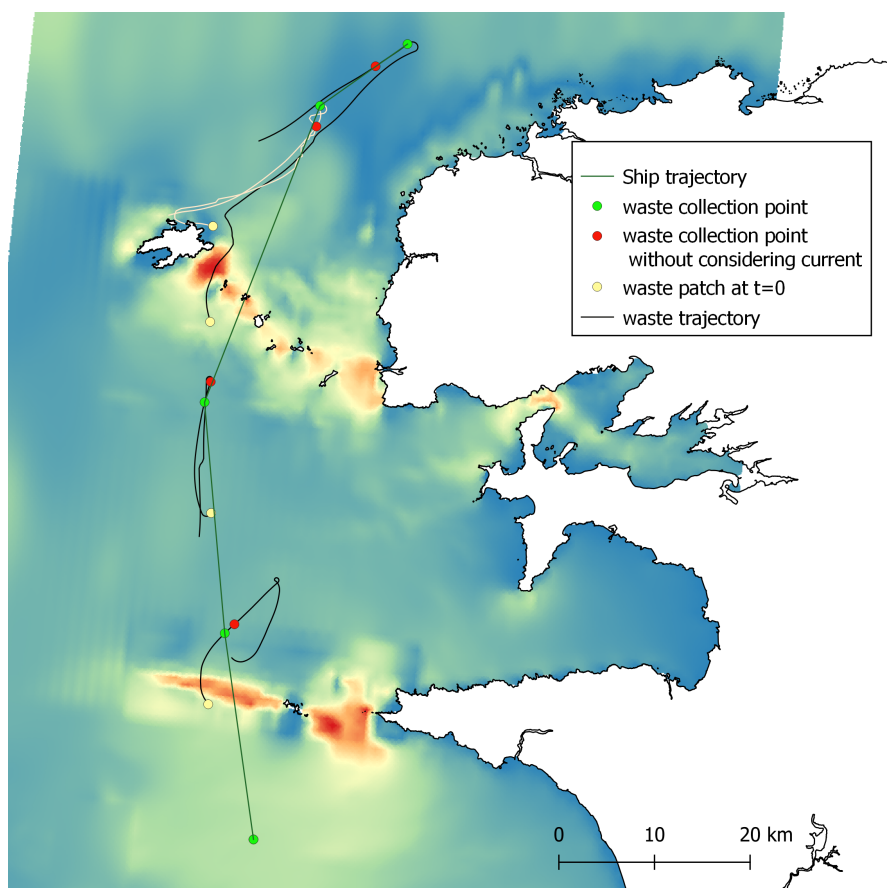

Fig. 9. Example of a ship trajectory for waste patch plastic collection

\section{Conclusion}

An integrated approach for the observation and recovery of plastic waste in marine environments has been developed in this paper. The approach is based on an dual extraction mechanism and a database model that allows to monitor and visualize the movement of macro plastic at sea. Two methods of current estimation have then been proposed, one called deterministic, which evaluates the velocity and direction of the current by spatial and temporal interpolations, while another called stochastic is applied according to a probability law. Finally, a first model of the boat's behaviour for the collection of waste patch at sea has been proposed in order to build optimal routes taking into account the current and the reduced capacities of the boat used.

Future work may include additional data (e.g., winds, tides) to refine and improve the plastic garbage drift model both at the observation and recovery steps. This drift model take a specific place in the process of data merging that also need to be developed. Also the model of macro-waste trajectory following its centroïd for its displacement may find its limits if the macro-waste considered is too large. Another alternative could be to consider a macro-waste as a subdivision of macro-wastes when it is too large, so a macro-waste can be split into several parts or merged with others. Different weights according to the quality of the observation and mechanisms to determine the identification of the same 
patch for two different observations might be also applied. Finally, the characteristics of the vessel must be taken into account (as well as collaboration between different vessels), in particular to estimate the vessel's sailing time, as well as the current when the vessel moves in order to be able to route the vessel as efficiently as possible.

Acknowledgment We would like to thanks Eric Le Plomb and Yannick Lerat of The SeaCleaners association for their discussions that greatly improved our understating of plastic debris issues in oceans.

\section{References}

1. UNEP: UNEP Year Book 2014 : emerging issues in our global environment. United Nations Environment Programme (2014).

2. Eriksen, M., Lebreton, L. C. , Carson, H. S. , Thiel, M. , Moore, C. J. , Borerro, J. C., Galgani, F. , Ryan, P. G. , Reisser, J.: Plastic pollution in the world's oceans : more than 5 trillion plastic pieces weighing over 250,000 tons afloat at sea. Plos One 9 (12), 1-15 (2014).

3. Browne, M. A., Dissanayake, A., Galloway, T. S. , Lowe, D. M. , Thompson, R. C.: Ingested microscopic plastic translocates to the circulatory system of the mussel, Mytilus edulis (1.). Environmental science \& technology, 42 (13), 5026-5031 (2008).

4. Öztekin, A., Bat, L.: Microlitter pollution in sea water : A preliminary study from sinop sarikum coast of the southern black sea. Turkish Journal of Fisheries and Aquatic Sciences 17 (7), 1431-1440 (2017).

5. Rojas, J.: Plastic waste is exponentially filling our oceans, but where are the robots ? In 2018 IEEE Region 10 Humanitarian Technology Conference (R10-HTC), pp. 1-6 (2018).

6. Cheshire, A., Adler, E., Barbière, J.: UNEP/IOC guidelines on survey and monitoring of marine litter. United Nations Environment, Programme/Intergovernmental Oceanographic Commission (2009).

7. Galgani, F., Hanke, G., Werner, S., Oosterbaan, L., Nilsson, P., Fleet, D., Kinsey, S. , Thompson, R., Palatinus, A., Van Franeker, J. A. , Vlachogianni, T., Scoullos, M. , Veiga, J. M. , Matiddi, M., Alcaro, L., Maes, T., Korpinen, S., Budziak, A., Leslie, H., Gago, J., Liebezeit, G.: Guidance on monitoring of marine litter in european seas. European Commission (2013)

8. Lippiatt, S., Opfer, S., Arthur, C.: Marine debris monitoring and assessment : Recommendations for monitoring debris trends in the marine environment. Marine Debris Monitoring and Assessment. NOAA Technical Memorandum NOS-ORR-46, (2013).

9. Duis, K, Coors A.: Microplastics in the aquatic and terrestrial environment: sources (with a specific focus on personal care products), fate and effects. Environmental Sciences Europe,28(1), 1-25 (2016).

10. Sharma S, Chatterjee S.: Microplastic pollution, a threat to marine ecosystem and human health: a short review. Environmental Science and Pollution Research, 24(27), 21530-21547 (2017).

11. Maximenko, N., Hafner, J., Niiler, P.: Pathways of marine debris derived from trajectories of Lagrangian drifters. Marine pollution bulletin, 65, 51-62 (2012). 
12. Law, K.L., Morét-Ferguson, S., Maximenko, N., Proskurowski, G., Peacock, E. and Hafner, J., Reddy, C.M.: Plastic accumulation in the North Atlantic subtropical gyre. Science,329(5996),1185-1188 (2010).

13. Eriksen, M., Maximenko, N., Thiel, M., Cummins, A., Lattin, G., Wilson, S., Hafner, J., Zellers, A., Rifman, S.: Plastic pollution in the South Pacific subtropical gyre. Marine pollution bulletin, 68, 71-76 (2013).

14. Mace, T.H. 2011: At-sea detection of marine debris: Overview of technologies, processes, issues, and options. Marine Pollution Bulletin, 65, 23-27 (2012).

15. Jakovljević, G., Govedarica, M., Alvarez-Taboada F.: Remote Sensing Data in Mapping Plastics at Surface Water Bodies. Conference: FIG Working Week 2019 - Geospatial information for a smarter life and environmental resilience, Hanoi, Vietnam 22 - 26 April 2019.

16. Goddijn-Murphy, L., Peters, S., Van Sebille, E., James, N.A. , Gibb, S.: Concept for a hyperspectral remote sensing algorithm for floating marine macro plastics. Marine pollution bulletin, 126, 255-262 (2018).

17. Kataoka, T., Murray, C.C., Isobe, A.: Quantification of marine macro-debris abundance around Vancouver Island, Canada, based on archived aerial photographs processed by projective transformation. Marine pollution bulletin, 132,44-51 (2018).

18. Moy, K., Neilson, B., Chung, A., Meadows, A., Castrence, M., Ambagis, S., Davidson, K.: Mapping coastal marine debris using aerial imagery and spatial analysis. Marine pollution bulletin, 132, 52-59 (2018).

19. Blettler, M. C. M., Ulla, M. A., Rabuffetti, A. P., Garello, N.: Plastic pollution in freshwater ecosystems : macro-, meso-, and microplastic debris in a floodplain lake. Environmental monitoring and assessment, 189(11), 581 (2017).

20. Carlson, D. F., Muscarella,P. A. , Gildor, H., Lipphardt Jr, B. L. , Fredj, E.: How useful are progressive vector diagrams for studying coastal ocean transport ? Limnology and Oceanography: Methods, 8(3), 98-106 (2010).

21. Castro-Jiménez, J., González-Fernández, D., Fornier, M., Schmidt, N., Sempéré, R.: Macro-litter in surface waters from the rhone river : Plastic pollution and loading to the NW mediterranean sea. Marine Pollution Bulletin, 146, 60-66 (2019).

22. Shen, Y.-T., Lai, J.-W., Leu, L.-G., Lu, Y.-C., Chen, J.-M., Shao, H.-J., Chen, H.W., Chang, K.-T., Terng, C.-T., Chang, Y.-C., et al.: Applications of ocean currents data from high- frequency radars and current profilers to search and rescue missions around Taiwan. Journal of Operational Oceanography 12 (2), 126-136 (2019).

23. Wichmann, D., Delandmeter, P., Dijkstra, H. A., Sebille, E. v.: Mixing of passive tracers at the ocean surface and its implications for plastic transport modelling. Environmental Research Communications, 1(11), 115001 (2019).

24. Jinman, K., Gajera, K., Cohen, I., Medioni, G.: Detection and Tracking of Moving Objects from Overlapping EO and IR Sensors. In Conference on Computer Vision and Pattern Recognition Workshop (CVPRW), pp 123-123 (2004).

25. Salmon, L., Ray, C., Claramunt, C.: Continuous detection of black holes for moving objects at sea. In 7th ACM SIGSPATIAL International Workshop on GeoStreaming, pp-2 (2016). 